UNIO - EU Law Journal. Vol. 4, No. 1, January 2018, pp 27-44.

(2018 Centre of Studies in European Union Law

School of Law - University of Minho

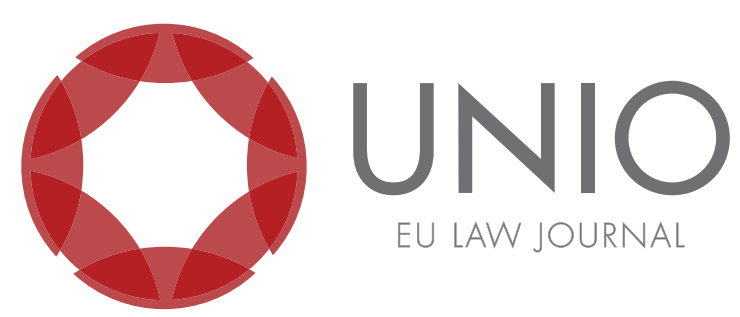

\title{
Understanding political beliefs: advantages and conditions of a culturalist notion of an event
}

\author{
Yanko Moyano Díaz*
}

ABSTRACT: This paper departs from the assumption that the construction of Europe - a complex project that mixes cultural, political, social, and institutional dimensions -, cannot be planned nor developed while ignoring the relation between actions and beliefs. To address this requirement, it is essential to establish an epistemological space in which the different levels of political activity and political thinking can converge and communicate the following: (i) the level of concrete political actions; (ii) the level of the general mechanisms of understanding and; (iii) the level of the experience of daily lives of its citizens. Then, we propose a conception of an event, taken from the contemporary French historiographic school. We will attempt to illustrate its potential for the study of political understanding and defend the convenience of adopting it as a starting point in the construction of an open epistemological space - one that can be shared by the different disciplines that approach the field of politics.

KEYWORDS:political believes - political culture - cross-disciplinary - cultural turn - subjectivity.

\footnotetext{
* Tutor at the UNED, Spain. Has a Degree in Philosophy from the University of Havana (Cuba), Master in Philosophical Studies from the University Alberto Hurtado (Chile) and PhD at the University of Barcelona (Spain).He has been professor at the University of Havana, at the Instituto Superior de Arte (Cuba) and at the University of Barcelona, Spain.
} 


\section{Introduction}

At least two of the most serious problems Europe faced in 2017 were the "Brexit" consequences and the dispute over sovereignty between the Spanish government and the Generalitat de Catalunya. Both share a revealing condition. They both started as conflicts whose roots deepen into the modern idea of a Nation and become global phenomena that affected European coexistence. Both impact the image of "Europe" as a political object and change the conditions of its analysis as a first order subject of the contemporary humanistic and social studies.

It is striking that both phenomena produced such mutually exclusive assessments of the qualities and benefits of being a member of the European Union. In one case, the British majority in the June $23^{\text {rd }}$ referendum supported anti-European trends, as it was their view that the UK's membership of the EU could be linked to the economic setback of middle classes in UK and has exerted an overwhelming - and negative - influence on national political affairs. In the second case, the discourse of the Catalan pro-independence supporters - at least in the early stages of the conflict - linked the idea of Europe to their demands for economic progress and democracy. Their supporters clearly preferred remaining within the Union - in the case of a hypothetical separation of Spain - and, when the conflict escalated during the last quarter of the year, their first reaction was to demand a mediation of the Europeans institutions. In one case, among the British, the majority view was that European institutions lacked political autonomy, opposed development and limited the will of the citizens. On the other case, for the Catalan pro-independence supporters, Europe was the privileged guarantor of the birth of a future European state, one of the conditions for its development and the only political actor who could and should facilitate the "will" and the sovereignty of the citizens.

Contradictions such as these give rise to some obvious questions: Wish is the "real" Europe? What do its institutions mean when they say "...for the citizens of the Union as a whole?...". Is there any unified answer to these questions or are these contradictions the result of some kind of "double personality" disorder? Perhaps, as some populist interpretations enact, should we accept that there is a Europe for the nations of the South - which is "taking advantage" of the benefits of the Union - and there is another Europe for the nations of the North - which are inundated with the lion's share of the responsibilities and, consequently, suffering the disadvantages of integration?

\section{Political beliefs}

Each of the decisions that form part of the political life of the communities are determined by what their members "rationally" wish to achieve and by the non-rational conditions of their actions, usually associated with, but not limited to, affective reactions produced on the daily life of the people involved. This is particularly noteworthy when reviewing complex political phenomenon, as is the case with the contradictions around the idea of Europe and its impact on national political realities. The "non-rational" and "contradictory" character of these dynamics, however, does not mean these opinions and beliefs of citizens should not be taken "seriously" or that they should be corrected and changed by other ideas closer to the "true" reality. 
This paper parts of the assumption that political believes are not a "cosmetic" layer that covers a fundamental structure of "true" objective relations. ${ }^{1}$ To the contrary, through its influence in the formation of citizen's opinions and its importance in the construction of shared social meanings, it plays a decisive role on social perceptions, cultural decoding of actions, political decisions and - in the long term - the way commons institutions are shaped in time. The construction of Europe - being as it is, a complex project that mixes cultural, political, social and institutional dimensions -, cannot be planned nor developed, ignoring the relation between actions and beliefs. Nor can the questions on the meaning of Europe, as proposed above, be satisfactorily answered. ${ }^{2}$

A first step in attempting to comprehend the sometimes contradictory behavior of political beliefs is to abandon the idea that the assertions on which it depends may be constricted to any form of boolean space, determined only by "true" and "false" options. In other words, it is crucial to abandon the attempt to demonstrate that some beliefs are "wrong" and others are "correct", hence force the subordination of one to the other. A particularity of this type of political assumptions is that they "operate" outside epistemological parameters defined from the point of view of scientific rationality. Instead, it depends more on states of opinion, citizens' perceptions of their immediate environment and the interpretation of situations they have in their own lives.

From this point of view, the study of the understanding of politics or what is the same thing, the analysis of the conditions of our political beliefs, is also a new "chapter" of the always contradictory relations between the knowledge that philosophical thinkers had been calling rational and objective throughout the lasts five centuries - more formal, regulated and recognized by distinctive tradition and the practical knowledge, only recently integrated at the core of social sciences, regularly "used" in the spaces of everyday life and produced in the whirlpool of personal experience. This opposing relationship goes beyond any "simple" disciplinary overlap. It ultimately leads to a deeper challenge: to make explicit the unavoidable dialogue that always exists - beyond any conscientious perception in the practices of politics. A not always friendly dialogue, established between what belongs to logical-scientific rationality and what is "outside" of it, between what is disciplinary and what is not, between the knowledge that has already been formalized by the different disciplinary traditions and what, according to the general model of modern episteme, is still waiting to be incorporated to the order of intellection.

Hence, one of the most complex issues in the disciplinary renewal of the field of politics is to clarify this "connection" between rational knowledge and everyday experience. But also - and for that reason -, this is one of the most important conditions when analyzing the foundations of the study of the comprehension of the political phenomena of the present.

\footnotetext{
${ }^{1}$ See Ernesto Laclau, La razón populista (México: Fondo de Cultura Económica, 2005). Also, George Lakoff, The Political Mind: Why You Can't Understand 21 st Century American Politics with an $18^{\text {th }}$-Century Brain (New York: Viking, 2008).

${ }^{2}$ Giovanni Capoccia and Daniel Ziblatt, "The Historical Turn in Democratization Studies: A new research agenda for Europe and beyond" in Special double issue of Comparative Political Studies, 43 (2010), no. 8/9.
} 


\section{The cultural-anthropological perspective as a conditioning factor of contemporary political studies}

At this point, it is clear that the answers to the questions we presented at the beginning of this paper, require a definition of the relationship between the political actions, the general mechanisms of understanding and the experience of the daily lives of EU citizens. To do so, it is vital to find a way to define what kind of "facts" are the ones that traverse these three distinct epistemological spaces, and to do this, the first thing is to understand the conditions that "define" the point of view from where this is possible. Hence, from here on, we will start with a brief description of the most general of these conditions: the culturalist perspective.

From the second half of the $20^{\text {th }}$ century onwards, important changes took place in the organisation of societies and in the epistemological principles that guided social, cultural, and political research. The new trend led to reinforce the idea that cultures $^{3}$ could not be simplified and were mutually immeasurable. Therefore, they couldn't be minimized or undervalued. In other words, from that moment on, cultures cannot be diluted nor converted into "parts" of more generic historical processes. Also, from that time onwards, it was popularized a radical criticism against the "overwhelming" character of terms such as bumanity or civilization and, on a higher theoretical level, against the negative effects of any forms of "conceptual" generalisation - both in academic activity and in everyday language.

Aside from the spaces of intellectual and academic production, the social reality of the 1960s and 1970s also pushed in the same direction. These were the years of the regression of the Fordist model in the corporate organisation and, with it, the old values of work associated with mechanical repetition and the classical industrial society. Discipline, hierarchical respect, perseverance, and self-sacrifice, for example, began to be replaced by new values such as creativity, innovation and individual initiative, all of which were distinctive of a more flexible, less centralized era, which personified a retreat from the logic of serial and mass production. ${ }^{4}$

These were also the years in which feminism began to stop demanding abstract equality between men and women - more or less undifferentiated - and began to claim the sufficiency of a female identity as a value in itself. In this redefinition, women began to define a new status and a new type of acceptance that would include the recognition of their differentiated contribution to the new social space. In other words, also in the speeches on gender equality, the idea that began to take hold was that the reaffirmation of equality is conditioned on the recognition of differences. In that sense, the constitution of new identities was the first step in securing any profound change in social attitudes; specially, a change that would guarantee women a new way of understanding themselves and being understood by others. ${ }^{5}$

The same was true in the case of the civil rights movement in 1960s America.

\footnotetext{
${ }^{3}$ In general, culture is conceived as the different sets of practices, precepts and shared notions around which community life organizes itself. This conception has a strong connection with the works of Clifford Gertz, La Interpretación de las culturas (Barcelona: Gedisa, 1981), but it is not limited to one author. On the contrary, it marks a general trend that clearly distinguishes the new approach to social science from the second half of the 20th century, see Victoria Bonnell and Lynn Hunt (ed.), Beyond the cultural turn: new directions in the study of society and culture (Berkeley: University of California Press, 1999). ${ }^{4}$ Peter Drucker, The Age of discontinuity: guidelines to our changing society (London: Heinemann, 1969); Gonçal Mayos, "Vulnerability and social change. From pre-Fordist era to post-Fordist capitalism" in Law \& Vulnerability. Research Seminars 2015 (Centre for Graduates Studies in Law - UFMG).

${ }^{5}$ See Judith Butler, Lenguaje, poder e identidad (Madrid: Sintesis, 2004).
} 
Step by step, demands for cultural recognition became more important and with it, the perception that it is not possible to speak of social equality without an implicit reflection on how a given society resolves the problem of co-existence of multiple identities or how it channels the particular concerns of those who feel marginalized. ${ }^{6}$ At the same time, "alternative" ways of seeing and explaining the world were gaining in value and attention, many of which were not necessarily subordinate to the general principles of logical rationality and scientific thought. In general, a kind of "rebellion of singularity", of what is different, of what is exceptional, took on prominence; it implied a re-definition of the value of the unrepeatable and of everything that cannot or does not want to be subjected to series, to regularity.

Also - and as a consequence - social research found, at its disposal, a large number of new objects of study, impossible even to imagine within the "traditional" paradigm, which was, in effect, just a few years earlier. In addition to the innovations already mentioned -daily life, language and significance- there were others, such as new studies on the city, ${ }^{7}$ sexuality, ${ }^{8}$ the body, ${ }^{9}$ imagination, ${ }^{10}$ intimacy ${ }^{11}$ and on alternative forms of economic development ${ }^{12}$ - among many others - that until then had only appeared sporadically or had been completely ignored in most of modern academies and universities. From then onwards - and in a short time - they expanded and became completely consolidated lines of research, which gradually developed their own work styles and gave rise to new research strategies. This marked the beginning of a new period - more open and dynamic - that re-opened the debate on the relations between the everyday life environment, its demands for explanation and the theoretical problems that human and social disciplines had to raise.

However, the new approaches also led to a difficulty. The new "things of the world" - the enunciation of new objects of research once "rescued" in their singularity - could multiply to infinity and seriously hinder the rational comprehension of the present - as a unified perception -, to the point of making unfeasible the relations between experience, discourse, and direct political action. It should not be forgotten that, at that time, the interest in spreading new discourses of identity recognition were as relevant as personal involvement in the rebellion against the established order and in favor of egalitarian development, the decentralization of power and the redistribution of economic benefits. Under these conditions, the theoretical problem of the unified apprehension of what is happening in the world - the eternal

\footnotetext{
${ }^{6}$ "[...] To me we are the most beautiful creatures in the whole world. Black people. And I mean that in every sense. Outside and inside and to me we have a culture that is surpassed by no other civilization but we don't know anything about it. So again, I think I've said this before in this same interview, I think sometime before, my job is to somehow make them curious enough or persuade them by hook or crook to get more aware of themselves and where they came from and what they are into and what is already there and just to bring it out. This is what compels me to compel them. And I will do it by whatever means necessary." (Nina Simone interview Nina Simone: Great Performances: College Concerts and Interviews. [1968] iTunes, 2009).

${ }^{7}$ See Henri Lefebvre, El derecho a la ciudad (Barcelona: Península, 1969) and La Producción del espacio (Madrid: Capitán Swing, 2013).

${ }^{8}$ See Michel Foucault, Historia de la sexualidad (Buenos Aires: Siglo Veintiuno, 1999).

${ }^{9}$ See Jacques Revel and Jean-Pierre Peter, "El cuerpo. El hombre enfermo y su historia" in Jacques Le Goff and Pierre Nora (eds.), Hacer la historia (Barcelona: Laia, 1979).

${ }^{10}$ See Paul Ricoeur, Ideología y utopia (Barcelona: Gedisa, 1989).

${ }^{11}$ See Philippe Ariès and Georges Duby (dir.), Historia de la vida privada (Madrid: Taurus, cop. 2001).

${ }^{12}$ See What now? The 1975 Dag Hammarskjöld Report on development and international cooperation (Uppsala: Dag Hammarskjöld Foundation, 1975) and Development Dialogue (Uppsala: Dag Hammarskjöld Foundation, 1985).
} 
philosophical problem of the relationship between logos and physis - and therefore, the problem of the coherent and extensive definition of social event - in a certain way, the problem of the subjective - objective unity of social and humanistic knowledge became an even more complex issue and a question of the greatest urgency to be dealt with.

Thus, from the second half of the $20^{\text {th }}$ century onwards, as part of a more general process - which we shall call, in a reduced manner, Cultural Turn - a challenge was posed to social theories. A challenge of such importance that today is still very difficult to approach. At the center we find the urgency to re-define the notion of social events and the need to revaluate its function as a primary unit of analysis. In other words, we are still facing a problem that can be summed up in the following question: how can we approach the explanation of society and politics without reducing the uniqueness of the different moments that constitute it (the singular events) and without renouncing, at the same time, the integrating aspiration that demands a global understanding of what is happening in the world?

\section{The re-definition of the event, an entry point for the political studies of the present time}

Having stated these difficulties and having reviewed some of the conditions that emerge from the culturalist perspective, it is also important to ask ourselves how to define the "facts", the raw material from which research on contemporary political beliefs is "nurtured". These "facts" that, as we said before, need to traverse the epistemological space formed by the triple confluence of: political actions, the general mechanisms of understanding and the experience of daily life of the citizens of the European Union.

The publication of the $18^{\text {th }}$ issue of Communications ${ }^{13}$ is part of this collection of dissonant notes that marked this Cultural Turn, and boosted the transition to a new social and humanistic paradigm during the 1960s and 1970s. ${ }^{14}$ The issue was dedicated exclusively to the event (événement) and it features texts by several authors who would consolidate themselves later, working within this new direction - for example, Edgar Morin, ${ }^{15}$ Emanuel Le Roy Ladurie ${ }^{16}$ and Pierre Nora. ${ }^{17}$

Briefly, the general intention of the publication can be summed up as a kind of proclamation in favour of the return of the event or, in other words, against the banishment to which the historical facts had been condemned by the historiographical model of the second generation of the Annales school. A new "return", however, that did not imply a revalidation of the past. On the contrary, far from vindicating the old days of "political" and "narrative" history, the goal now was to defend the possibility - and necessity - of a new historical perspective.

\footnotetext{
${ }^{13}$ Communications, 18, L'evenement. (École Practique des Hautes Études - Centre d'Etudes de Communications de Masse, 1972), accessed november 1, 2014, http://www.persee.fr/web/revues/ home/prescript/issue/comm_0588-8018_1972_num_18_1)

${ }^{14}$ Peter Burke, Formas de historia cultural (Madrid: Alianza, 2000).

${ }^{15}$ Edgar Morin, "Le retour de l'événement", in Communications - L'evenement, 18 (1972) : 6-20. Also,

"L'événement-Sphinx" in the same publication, 173-192.

${ }^{16}$ Emmanuel Le Roy Ladurie, “Evénement et longue durée dans l'histoire sociale: l'exemple chouan”, in Communications - L'evenement, 18 (1972) : 72-84.

${ }^{17}$ Pierre Nora, "L'événement monstre”, Communications, 18 (1972). L'evenement (École Practique des Hautes Études - Centre d'Etudes de Communications de Masse), 162-172.
} 
Among these articles, perhaps the best known - and also the most influential - is that of Pierre Nora, which is entitled " $L$ ' événement monstre". ${ }^{18}$ In it, its author starts from the analysis of the new status of the event in contemporary societies, its relationship with the increasing political participation of the masses and the increased political influence of the new communication system - at the beginning of the new TV era. Within this theme, so general and so frequently approached, the first striking feature of the article is that it moves away from the most common approaches. Instead of limiting itself to a critical analysis of the distortion surrounding the "event" or the effects of the rise of the political role of Mass Media, it reverses the point of view and focuses on the enormous epistemological potential of the event, just as it appears through the media, without seeking its purity or "objectivity".

The first thing that Pierre Nora emphasizes in this contemporary event are two characteristics that stem precisely from his high level of mediatisation: first, his "proximity" and, second, what he calls his "monstrosity", or more precisely, his "monstrous" magnitude.

In relation to the first characteristic, the "proximity" of the contemporary event, the almost immediate reception of what is "happening" -thanks to its diffusion in the news, for example - produces an illusion of participation in the spectator. In front of television, what happens in the world is literally happening in front of his eyes. To be aware of information is to "keep up to date" and to ignore it is to live "out of reality". If we add to this the speed at which the contents are reproduced and the exponential trend at which the references to them are multiplied, we become convinced - even if only by a kind of flooding effect - that we only live in reality "through" the reception of the event.

In many cases, going a little further, the notion of reality itself "merges" with these transmitted events and creates a false representation of the totality. Thus, it is not uncommon for contemporary societies to replace the answer to the question "what has happened in the world today?" with the outcome of the question "What has the news broadcast transmitted as a summary of the day's most important events?" In the end, is there any relevance? Does it really happen, is there as an event - and also as a social fact - whatever has not been transmitted, referred to or shared in the communication system?

This "participation" is also produced with a degree of "vivacity" and closeness that tends to erase the distance between the origin of the event, its media representation and the perception of the receiver of the information. Watching the newsreel, all the "elements" are present in the same room and coexist in time: the protagonists of the news are interviewed or appear in the image, the journalists of the newscast make an effort to ask the questions that the viewer would ask, and the commentators attempt to take into account the "public concern" in their analyses. Through all of this, the spectator feels as if he or she is participating in the event, "as if he or she is there". Finally, the different news stories also gather all the details already converted into a unit: a narration with beginning and end, logically ordered and with a well clarified and repeated proposal of meaning.

Thus, in the midst of the innumerable different perspectives that are diffused of the events, the more the contents accumulate, the more agile their "re-vision" seems to be, and the more "faithful" the image is re-transmitted, the less distance there is between the referred situation - the pretended "original facts" - and its reproduction. Actually, the more different edges of the event "pick up" the spectator,

\footnotetext{
${ }^{18}$ Pierre Nora, “L'événement monstre”, 162.
} 
the more he or she feels the event is within his reach as it happened. In other words, the event becomes more "real" in the media - in the sense of "evident" and "present" - and through this "reality" grows its presence in everyday life. Thus, it reduces the possibility of what Berthold Brecht called the "distancing effect", ${ }^{19}$ in this case, the one that should exist between the person-spectator and the happening-event.

In relation to the second characteristic, the "monstrosity" of the contemporary event is "close" and "vivid", while at the same time being "gigantic" and "disproportionate" - encompassing two meanings of the word "monstrous". The cause is also its close relationship with the whole mechanism of media dissemination and its multiplier effect. Everything related to Mass Media is, as the term itself indicates, "massive". A television broadcast reaches millions of people simultaneously, the world's leading newspapers count their editions on the same scale, and the influence of news agencies clearly exceeds these figures.

As a result, contents that are similar or very close to each other also arrive in a way that is quite similar to a large number of people. In this sense, while the event grows, it also becomes homogeneous. This not only multiplies the influence of the media - as described to the point of exhaustion in recent years - but also multiplies the importance of the event as an abstract social object.

Now we will see that this can be taken also, as an access route to the study of political representations of daily life, without abandoning the study of the general principles of understanding neither reducing them to a sum of generalities. In other words, we will see how it leads to postulate a kind of "social fact", open to the different planes that converge in the study of political beliefs.

From a quantitative point of view, the importance of the event as an abstract social object derives directly from its own "exaggerated" dimension. The more one or several events are repeated or the more abundant their presence becomes, the more the rest of the social objects "adapted" to it. In view of the exaggerated repetition of content, the most efficient - from the point of view of communication - is to explain and understand any of the other (less known) everyday matters, starting from the one that is best known. In this way, all the "minor" contents are usually understood in relation to the "bigger" content and from it, they receive an increasingly important part of their determinations - all of this without a critically thinking about it. In the end, it becomes increasingly difficult to refer to other social objects without the "overlapping" presence of the "main" event.

This pushes the "central" event to occupy an ever-growing space and to have an ever-increasing "weight" within the collection of social objects of everyday life. As a kind of "black hole" of information or as a gravitational center that makes the rest of the daily facts revolve around it, the (over)sized events modify the contents of their environment and if, for some reason it is missing, it would inevitably leave a greater void.

Thus, these media over-dimension of the event is never "mere illusion". On the contrary, the more repetitive is its presence, the more necessary that event becomes in explaining the social dynamics of which it is a part of. The same thing happens in the realm of political beliefs. The most mediatic events are also the most important in the network of symbolic meanings that make up the representation of the person's

\footnotetext{
${ }^{19}$ Bertold Brecht, "Alienation effects in Chinese acting" in Brecht on theatre. The development of an aesthetic, ed. John Willett (London: Methuen, 1964), 91-99 and "Short description of a new technique of acting which produces an alienation effect" in the same publication, 136-147.
} 
environment. In general, they are also the ones that influence the most in all cultural processes, through which the whole system of social representation is displayed and reproduced. For this reason - and from a qualitative and more personal point of view - the more vivid the "monstrous" event is, or what is the same, the less critical reflection it mobilizes - as we explained before -, the more decisive it ends up being in relation to the individual mechanisms of social interaction.

In direct contact with the event, the "immediate" life is codified increasingly in relation to it - or better said, it is meant in relation to the event. Then, the event increases its presence in speech and increases its use as an element of interpretation. It appears more as a common reference, as a key to explain and understand what happens to other people we know. In this sense, it is increasingly becoming a conditioning factor of the immediate experience.

This increased importance of the event as a "vivid" and "monstrous" event also has another consequence. The more uniform and more important the events that are repeated in each newscast become, the more eye-catching are the alterations of it that may appear or what is the same, the greater value acquires "the exceptional" once it succeeds in emerging. Consequently, more noteworthy are the singular, distinct events, and greater are the impact of the "debates" around them.

It is this phenomenon that explains why some emerging political experiences manage to "equalise" the power of traditional institutions in the field of information. As a little further on, phenomena such as the Zapatista guerrillas and Cuban bloggers acquire relevance and visibility thanks to their ability to surprise, alter the representation to use and provoke a disruption. Internet and social networks amplify this effect, but the basis remains the same as P. Nora postulated in his event model in the early 1960s. The contradiction between the "monstrous" presence of the mediatised event and its tendency towards homogeneity, which hinders its action as a central element of interpretation in everyday life - infinite - and creates a need - a demand for novelty -, always growing and impossible to satisfy completely.

Maybe that's why TV newscasts and newspapers, "instinctively", try to present each event as an extraordinary event, although they don't always manage to present as such. In most cases, the bulky headlines end up being forgotten in a short time and the only thing that remains is a general feeling of being the subject of a great staging, sensational, false, and often overwhelming. However, and without denying the seriousness of this situation, this general "gamble" on exaggeration should not lead one to underestimate the importance of the event and its profound impact on the understanding of the social environment.

The event, "turned" into a spectacle or "born" as a spectacle - it doesn't matter much - always becomes a "social fact" of the utmost importance. And this happens regardless of the "original" intention of the media that gave it the "initial" notoriety. Its importance is due to the fact that, socially, the event ends up fulfilling a dual function: it allows the individual to live in history - to recognize himself in a changing and transforming world - and it gives life to history - becomes the vehicle of a narration, allows the historical and social causality to become "real" through the different representations of the present.

As Nora points out, this new situation of the event also reduces the historian's influence - and with it, that of all social and humanistic research - to almost nullify it. As it becomes more and more "present" - in its dual sense of "tangible thing" (that is there) and verbal time (which is now) - it also moves away from the expert arrangement 
of the historian and from the scientific reconstruction. Also, the effects of the action of time on it are reduced, given the significant decrease of the time lapse between the "capture" of the "fact" and the reflection that analyzes and orders it. With this, it is no longer possible that "settlement" of "facts" which was so appreciated by the nineteenthcentury history - a lover of archives and method - as the best remedy against the chaos of reality. In this sense, it can be said, the logic of the ordering of events is far removed from the influence of the logic of scientific truth - episteme - and approaches to another logic, that of social imagination. How does this transit occur and what are its effects?

In the primacy of the événement monstrueux, Mass Media needs, above all, to present their contents in such a way that they reach the greatest number of people within their target audience and to do so in the most effective way possible. This goes above other qualities of information, such as "objectivity" truthfulness or ideologicalpolitical conditioning factors which, however, were more common at the time when the historian was decisive in the selection of the most relevant events. Although other needs also influence the news - television channels are not neutral entities and obviously, do not renounce to present their own interests - they generally operate in the background, since they need to adapt themselves first of all to the laws of entertainment and subordinate themselves to the rules of an attractive staging. Above everything else, the ability to be engaging is the first condition for content to transcend and without it, is impossible for it to multiply among the public and prevail amongst the numerous "competition".

A newscast without a public is quickly "out of the game". Regardless of whether it is supported by groups with economic power or by "special" interests. Without an "audience", it is not convenient to maintain such an expensive "resource" or, at the very least, its social impact is significantly reduced. The "reality" of information offered by the media today is distributed through so many channels, so many options are available to consumers - multiple television stations, Internet, social networks, the fluidity of personal data exchanges, etc. - that only the most "effective" media can have a significant public influence.

Thus, although it is true that the événement monstrueux already presupposes an intervention of the Mass Media and that, therefore, they would have "guaranteed" their direct influence on the contents that are broadcast, it is no less certain, too, that as producers of a "show" - the barrier between public service and spectacle is increasingly weaker -, they are inexorably conditioned by certain "rules of the game" or, more specifically, by certain "rules of the show". Rules that operate above the will of publishers, producers and CEOs and that refer directly or indirectly to the expectations, life stories, imaginations and ambitions of the communities they target. Ultimately - it can be said in various ways - they form part of the system of cultural objects, are conditioning factors in the worldview of a group of people and are distinctive elements of each specific cultural identity.

Following this dynamic and interested in increasing their capacity to reach the public, the Mass Media accelerates the occupation of the "emptiness", meets expectations; they distribute themselves through the spaces of influence or compete for them. In all cases they condition themselves according to the different modalities of social imagination. They also adapt and adapt the arrangement of the event according to the requirements of each of the niches they intend to "reach". Thus, at the same time that the event-happening is reproducing itself more and more efficiently, it also opens the 
door to a greater public participation - a limited and certainly indirect participation, but participation at last.

In a nutshell, to the extent that the event moves away from rational ordination the field of influence of the social researcher -, it is "liberated" to receive the influence of culture and social imagination, which are paradoxically present through the greater presence of the Mass Media. As Nora says, in every event, the imagination of the mass wants to insert something of itself and it is through this insertion that daily life communicates with the global system of culture.

When the the événement appears, almost by its own definition, it is always a disruption. And it is in this disruption and not in its subsumption within a general theory of society and the world that lays its potential as an object of study. The event - to a greater or lesser extent - is always disturbing, questioning, and the cultural re-production of the "real fact" as event almost always responds to its potential to stand out from the rest.

Sometimes this disruptive exceptionality is evident, because the eventis immediately shown as the dissonance of a series, "the grain of sand from the machine, the accident that upsets and suddenly surprises". ${ }^{20}$ Other times, however, it seems that the event does not contradict but confirms a story -history already known and previously admitted. This story-history seems to already contain it. It seems like the event can replace the whole story-history and send it into the background. However, it is thanks to the event and through it that the various synthetic images of the world are disseminated and come to occupy a prominent place in the representations. In these cases the event acts a representation of all diversity. It transcends as a sort of summary of what is happening. In this sense, it is also a disruption. It stands out as a symbol and concentrates on itself all looks and questions. It breaks the regularity of the "normal".

It is this disruptive capacity that gives the event its greatest potential as an object of study for social research. In the summum of its success, the event cancels the rest of the "bistory" and takes its place. The historical explanation, with all its contents and questions, turns around and becomes a "story" about the events. From this point onwards, it becomes an invitation to review the baseline content of all existing social and political research and, in a special way, it also opens the possibility of an unforeseen change in political opinions at the level of everyday life.

In its "awkwardness", the event always exists as a disruption because there is a "normality" in which it does not fully fit and against which it conspires. On the one hand, this "normality" tries to annul it, if only because of the tendency of historical processes to evolve according to a path dependent ${ }^{21}$ pattern of development. On the other hand, the event can never concentrate absolutely all the attention or detach itself completely from "normality", because event needs it as a reference from which to stand out.

The key is to understand that the moment of "reception", at least in contemporaneity, is not merely a "receptive" moment. On the contrary, the way it works expresses the social imagination and a form of interpretative action that is intrinsic to the public life. Moreover, it has a decisive influence on the cultural

\footnotetext{
${ }^{20}$ Free translation from: Pierre Nora, "El grano de arena de la máquina, el accidente que trastorna y pilla [sic.] de improviso" in La vuelta del acontecimiento, Hacer la historia, ed. J. Le Goff and P. Nora (Barcelona: Editorial Laia, 1980), 232.

${ }^{21}$ Paul Pierson, "Path Dependence, Increasing Returns, and the Study of Politic" (Jean Monnet Visiting Professor Lecture. European University Institute, April 1991) and Politics in Time (Princeton University Press, 2004).
} 
mechanisms of production of meanings. "la realidadpropone, el imaginario dispone". ${ }^{22} \mathrm{Or}$ in other words, the event-happening acts as an interaction device that orders public reality from "down" to "up".

The event, thus, becomes the meeting point of two "universes" that were very difficult to combine throughout modernity. On the one hand, the notion of event opens the door to what Pierre Nora calls the study of the "formal phenomenology of the event", on the other hand, it also opens the door to the study of what he called "the system of significance". The first is related to the critical description of the processes of production, diffusion and reception of the event, the ways that make it possible, the interests that intervene in its formation; the event considered as a particular fact. This is the place of history "told", formed by the succession of events. The second relates to the study of the network of signs and contents that intervene and condition representation processes. This is the "bidden" side of the event. The space where the relations between "objects" precede the consciousness and where there are no protagonists or intentions. Here, events cannot be ordered in succession. Its study is that of synchronous or quasi-synchronous structures - an access to the so called longue durée. ${ }^{23}$

This double-sided dimension of the event makes it a bridge between the two research models that were in conflict at the time the cultural turn arises. On the one hand, sociology and structuralism, on the other, the demand for singularity and the demand for the study of divergence - of phenomena considered minor or dependent. For the first model, culture was a system whose development followed general laws. For the second, it was daily practice, a shared experience, formed by the "little" artifacts and the "small" actions that filled everyday life. The new model of event opened an alternative, since it proposed to deepen the study of the "system" of culture as a conditioning factor of the immediate reality, but without having to accept its precedence or its autonomy with respect to daily life.

While we are sure - almost "naturally" - that the world is in constant transformation and that today's reality is a transitory state of what has come to be known as the "movement of history". This "movement" only becomes "perceptible" through the event reproduced by the mass media. It is through him that history becomes real, that it becomes consolidated as a concrete experience that embodies the immediate perception of change and the pre-established idea that modulates it. With the reception of the event, historical change as a general notion ceases to belong to the set of "known notions" and cultural assumptions and becomes part of everyday "reality". In other words, in the "mediatic" event the universe of precomprehension becomes present, as news or information, becoming an element of judgment of the political and a subject of debate in everyday life.

\section{The subjective determinants of communication in the age of Internet and the new Media}

Let us now make a little temporary ellipse. Until the new era of digital media and internet communication. It is tempting to assume that in the new epoch, the conditions of the event have changed and this may lead us to think that the type of questions

\footnotetext{
${ }^{22}$ Pierre Nora, "La vuelta del acontecimiento...", 227.

${ }^{23}$ Ferdinand Braudel, "La larga duración" in La historia y las ciencias sociales (Madrid: Alianza Editorial, 1990), 60-106.
} 
that we proposed at the beginning of this paper must be answered in a completely different epistemological space. However, as we will show next, the new situation does not fundamentally modify the advantages of the model of event that we have just planned. On the contrary, we will show how it allows us to connect new concerns, such as, for example, those associated with the reception and dissemination of digital content, with certain components of the field of subjectivity formation and explain its impact on the formation of political opinions.

Here too, we must start from the recognition of a contradiction: the rising number of information providers, characteristic of the new Internet era has led to a greater democratization of the production of content - informative, cultural, interpersonal, etc. - ; however, the high acceleration with which these contents continue to grow and the disorderly accumulation of options available to the Internet user may also be causing an inverse effect: the impoverishment of the quality of communication and the obstruction of access to "truly" relevant information

One of the main features of this contradiction is the current situation of distribution channels and information mediators that were previously hegemonic. The change in recent years has not occurred so much because the smaller media - which were marginalized for economic, managerial or ideological reasons - have been able to "level the playing field" with respect to the larger media, but because the new situation has multiplied the importance and consolidated the space of a new type of information provider: the isolated individual. The big difference we find today is that he is now able to produce and distribute content more easily than in the past and also to establish more direct relationships with the audience.

Consequently, - and this is where the heart of the contradiction lies - the greater "democratization" of content broadcasting in recent years may not be leading to a desired increase in the diversity of ideas in circulation, nor to an effective expansion of access to cultural innovation spaces. Rather, it would have opposite effect, a "flood" of communication channels, and a saturation of options for understanding the environment in which more disordered, redundant and futile content accumulates, which in the long run, only causes noise and distortion.

During the era of the modern Nation-State's heyday - at the end of the nineteenth century - cultural institutions functioned as filters of information and guaranteed an order that, as is well known, had its difficulties, but also offered its own advantages. They hierarchised the contents according to criteria of social, cultural, and political relevance that they themselves designed. Through them, a canon was established, competencies were distributed and the trust that the different sources of information deserved was qualified. They also arranged the possible interests of the recipients of the information - for example - into predefined thematic packages. Now, these "advantages" have disappeared. They led to an overly restrictive model - from a contemporary perspective - which reduced the scope for individual action and the space for creative initiative; thus also impoverishing the collective capacity to produce innovative content and slowing down the speed at which new ideas spread. Both are essential preconditions for the organization and growth of post-industrial society.

In recent years, the loss of the influence of traditional institutions, the impact of the bursting of circulating content and the multiplication of person-to-person information distribution networks have radically changed the information dissemination model. But they have done so in a way that has given rise to new problems. Today, we find an information user who is freer, more "connected", but also - paradoxically - more 
"lonely". Especially if we consider how much he has lost in terms of the influence of the innumerable layers of history and tradition that had previously accumulated traditional institutions, that had been condensed in the form of regulations and had been transmitted to each of the individuals who related to them in their daily activities. In the absence of reliable institutions, this user now seems to be "abandoned" to recreate - every time- the cultural evaluation criteria and to re-produce - every time the selection mechanisms based on totally personal criteria, modelled in a much more contingent causality and dependent on each of the different nearby environments $-\mathrm{e}$. g., tunnel effect.

Hence a major feature of the new information society, the increased importance now held by the ability of certain contents to stand out "for themselves", to become more "present" than others, influencing many people, each individually and without the need to rely on the influence of historically established cultural institutions. This capacity also functions at a more intimate and personal level; strengthened based on "intuitive" criteria, almost never rational and only partially and indirectly connected to the old collective mechanisms of mediation and information management. Precisely for this reason, as we shall see below, the understanding of its functioning refers to the study of some more general conditioning factors of subjectivity and culture, which are usually considered in the field of philosophical studies. In so doing, it once again shows its relevance to the more contemporary field of understanding political beliefs.

Two political experiences exemplify the new situation, confirm this hypothesis and could serve as a guide to better understand the type of theoretical approach advocated in this paper. On the one hand, the Zapatista guerrillas; a political movement that had its maximum influence during the 1990s and for which the first stage of the Internet and the first advances in information technology were vital. After a brief period of armed confrontation with the Mexican army (January 1994), the guerrillas transferred their space of influence to the field of communication and cultural action, for which the new possibility of connecting quickly and directly with a receptive public was crucial. Thanks to their rapid "mastery" of the new virtual space - then still emerging-, they managed to overflow the Mexican space in a very effective way and were successfully projected as a new kind of political movement on a global scale. In fact, it was this ability to stand out and attract the attention of activists from around the world that served as the reason why they could maintain themselves as a viable political movement, since their military strength was quite inferior vis-a-vis the Mexican army.

One other example, very different and far more recent, is the movement of Cuban bloggers, especially around the blog Generación $\mathrm{Y}$, the most successful of the group, produced by political activist Yoanis Sánchez. In this case, the opportunities offered by new technologies and the existence of a new communication environment for disseminating content worldwide have also proved to be crucial despite Cuba's government control over the use of the Internet. This is mainly due to two reasons. Firstly, it has been the ability to connect directly with an "interested" audience that has allowed its authors to make their political opinions known - to do politics - and to overcome the obstacles with which the Cuban government blocks the dissemination of opposing opinions. Secondly, it has been this same direct contact with activists from all over the world that has allowed them to denounce the threats received and inform their audience of the periodical police actions with which they have been attempted to be suppressed. In many cases, it has been the fear of the global repercussion of the news that has forced the Cuban government to establish certain limits to the repression 
it exerts against them, keeping them "safe" and in a position to continue spreading their opinions.

Despite their obvious differences between these two examples -on technological dynamics, political alignment, political objectives, etc. -, it is striking to note that both cases depend so much and in a similar way on the same political resource: the place they managed to reach as relevant news content of international news or, in other words, the political visibility they have managed to achieve.

None of the political effects that they have had could have been achieved without this visibility, including the links they established with a sufficiently large and widespread worldwide audience interested in disseminating their opinions, pending their situation and willing to put pressure on their opponents. What made this "success" possible? Why did these movements - and not others - manage to catch the attention and place themselves on a par with government communication tools, which are much better endowed in monetary and technical terms?

In order to answer these questions, there are at least three conditions that must be taken into account, which are also relevant when explaining the more general causes of "interest" that are able to capture some projects in the field of political beliefs: innovation, public sharing of privacy details and help from the remnants of the traditional institutional network.

The first of the visibility conditions refers to the greater attention paid to those contents that break the continuity of the generalised model of the representation of reality. It could be said that these contents appear as an informative "novelty" and produce an impact that forces the re-composition of schemes. They generate a surprise that makes the "usual" interpretation impossible. This impact stems from the difficulty of connecting the new content with other information milestones that surround it and are more "habitual" and, therefore, a "challenge" to the imagination and a demand for new rationalisation. To understand them, it becomes necessary to revise, reconfigure or produce new relationships between the information that already existed. In general, it is a very similar experience to the one we mentioned earlier about the always disruptive impact caused by the growth of media events.

The mechanism that makes the effect possible is also very similar to the one that Paul Ricoeur described when analyzing the functioning of the metaphor. ${ }^{24}$ Based on the interpretative innovation required by the metaphor - understood as a tension between contradictory meanings - the reading of a text "opens" an interpretative arc that stimulates a hermeneutical process, which in turn leads to a rethinking of the relationship between the reader and the world around him. In our case, the tension arises from the incompatibility between what is expected to have happened, as a first meaning, and the difficulty of the new "data" provided by the "novel" information, as a second meaning. And it also leads to the postulation of a third meaning. In this case, it is produced by the reconfiguration of the interpretations and political representations that can be made regarding new phenomena. In other words, it is in the emergence of a "creative" meaning, that genuine political innovation occurs. And it is through it that citizens express their desire for change and participate in permanent social readjustment.

In the Cuban context - with an absolute control of the media on the part of the State -, the appearance of a "different" issuer of informative content, is an "event" in

\footnotetext{
${ }^{24}$ Paul Ricoeur, La Metáfora viva (Madrid: Ed. Europa, 1980) and El Conflicto de las interpretaciones: ensayos
} de hermenéutica (Bueno Aires: Fondo de Cultura Económica, 2003). 
itself. It is already a political innovation that distorts the representations of the "socialist" model. Only the fact that it exists, which is already surprising, attracts attention. It arouses curiosity and prompts debate, even before beginning the analysis of the concrete political contents of their proposals. It is not necessary for their propositions to attract attention, their very existence as a "different" political acclaim, novel, already fulfils this function. The fact that Cuban bloggers start with this kind of "advantage" is the only reason for their success, in the face of all government efforts to silence them. An effort that includes the broadcasting of special television programs during prime time, newspaper headlines and "political" comments in most education centers in the country - just to name a few examples.

The Zapatista guerilla also surprised and took advantage of a similar effect. His appearance at a time so close to the collapse of Soviet socialism, by itself, offered a riddle. How to name it? How to identify it? "Narcoguerrilla"? "Ancient Communism"? "Post-modern guerrilla"? It created a doubt, first and foremost, because they constituted a new reference, which contrasted with the announcement of the end of global confrontations, of the great stories of modernity and of the ideological polarization of everyday experience.

A second element that also stimulates the condition of visibility of the contents has to do with the seduction exercised among the general public by disclosing the details of private life and the possibility of giving a glimpse of spaces that "normally" remained more or less reserved to the eyes of strangers - according to an already "old" notion of privacy. ${ }^{25}$ John B. Thompson describes this process very well in two of his texts Los Media y la modernidad ${ }^{26}$ and El escándalo politico. ${ }^{27}$ From his point of view, the long process of the development of modernity is also, in his view, a long process of public exposure of the former sphere of private life; of advertising privacy. In the new contemporary public space, there are fused elements that previously - apparently were not of interest and these end up influencing citizens' decisions.

A paradigmatic example was the Clinton-Lewinsky case, which had an unprecedented impact in the United States. Any slight comparison between the debates surrounding this case and, for example, those that produced the Bush administration's "mistakes" a few years later, indicates a major difference and, at least, the existence of two completely opposite ways of signifying and evaluating what kind of actions become political scandals. It also reveals what kind of content has the most influence on the formation of public opinion: the voyeuristic morbidity that accompanies the seduction of advertising and stimulates moral stupor -in the case of Clinton- or the displeasure and irritation that could cause -but does not cause- the rational proof of having been deceived by political representatives, involving the country in an unnecessary war.

In the case of the examples presented above, the abundance of personal details

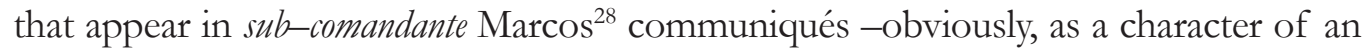
insurgent "fiction" and without reference to his "true" identity - favours the creation of a seductive sense of intimacy between the reader and the issuer of the political proposals. The same is true of Yoani Sánchez. ${ }^{29}$ She writes her political critiques in the

\footnotetext{
${ }^{25}$ Philippe Ariès and Georges Duby (dir.), Historia de la vida privada (Madrid: Taurus, 2001).

${ }^{26}$ John B. Thompson, Los Media y la modernidad: una teoría de los medios de comunicación (Barcelona: Paidós, 1998).

${ }^{27}$ John B. Thompson, El Escándalo político: poder y visibilidad en la era de los medios de información (Barcelona: Paidós, 2001).

${ }^{28}$ EZLN, "Cartas y comunicados del EZLN, 1994-2005."

${ }^{29}$ Yoannis Sánchez, Cuba libre: vivir y escribir en La Habana (Madrid: Debate, 2010).
} 
form of chronicles that reproduce the intimacy of her personal experience of Cuban reality. In both cases, personal representations quickly become the representation of a shared social reality - common to the author and the readers - and the identification between this public and private experience ends up being so "natural" that it is counterproductive to try to raise doubts about the correspondence between personal and general representation, since there is no epistemological condition involved that needs to be a guarantor of the veracity of the discourse.

This happens because the intimate discourse, in its exposition as a shared public fact, does not need to respond to the true-false dichotomy in order to be successful. It only needs to be accepted as next, possible, credible. Something that "could happen to me or my neighbor". And it does so when it produces a sense of sympathy between the reader's perception of his own intimate life and what he expects to be the other perceptions and the other intimate lives of his environment. At the end, this "reader" justifies a conception of the public space as it would be barely an extension of the shared space created by the "author". Hence a shared space "filled" not with political rationality objects but with generalized projections of his or her own, intimate perception.

But not all the power of the new type of information content on the Internet comes from the autonomous capacity for dissemination and social legitimacy that has reached the universe of new technologies. The growing interest in the phenomena related to political cyber-activism should not make us forget the strength and prestige still held by the traditional institutions involved in disseminating information. It should be remembered, for example, that Zapatistas' first contact with public opinion took place through "traditional' channels, thanks to the coverage provided by leading news media such as the Mexican daily La Jornada. Only later, a direct channel of communication was gradually established through the Internet, but by then, interest had already been consolidated.

Something very similar happens in the case of the Cuban bloggers. Although their starting point has been their individual vocation to express themselves in a personal and independent way, the group strengthens and gains diffusion capacity from the support they have received in the form of international awards and from the periodical references we find in the best established media. In this sense, it is very demonstrative, although not very novel, the strategy with which the Cuban government tries to annul the influence of the activists. Rather than directly attacking the content of blogs which then the government would be forced to reproduce - they concentrate on delegitimizing the awards they receive, revealing alleged sources of " unpatriotic" revenue, and publicizing their relations with political institutions that are easier to stereotype ideologically. This strategy clearly demonstrates the relationship that still exists between virtual activism "2.0" and the traditional institutions, on which an appreciable portion of its legitimacy continues to depend.

\section{Conclusions}

Although these conditions may well not be the only ones and without going into explaining the details of its operation, it is striking that his study was already developed in a very different time from the current one. At a time when neither the Internet nor the general model of communication currently in force had any influence on the reception and selection of information. However, its results can equally be applied to new phenomena, regardless of the fact that these now obey a very different logic apparently - to those that motivated its study. The reason for this confluence is that, 
in all three cases, the explanations of the processes of comprehension and reception of contents refer to the wide field of study of what philosophy has been called subjectivity and deal with the very general subject of the conditions of conformation and exchange of experiences in everyday life. These may be directly influenced and regulated (mediated) by rules imposed from the institutions or, more indirectly, by certain cultural traits that pervade all our actions imperceptibly. But, in any case, they are conditions that pre-exist to the will and conscious decision and certainly affect the entire selection of information that individuals carry out, including those they carry out "intuitively" on the Internet.

The definition above-mentioned of "event" offers a privileged path of access to the "deeper" side of the meaning of political opinions. In first instance, because it does not need to reduce all the mentioned practical experiences to "cases" of a more general phenomenon. On the contrary, these singular experiences become access points to the philosophical that distinguishes such a deep subject as the conditions of contemporary subjectivity. Thus, through the "returned" event, it is possible to maintain the co-existence of the two epistemological dimensions, that of meaning and that of everyday dynamics, without renouncing the singularity of both.

It is interesting to highlight this connection between Internet activity and studies on subjectivity, above all, because it gives a first idea of the "thematic" breadth and fields of knowledge that contemporary political studies, including the study of political beliefs, must address. Here too, the notion of treated event offers advantages. A study of visibility on the Internet cannot be limited to the study of behavioral trends of a "connected" individual, since it is not possible to separate it from the study of the general mechanisms of intuition-based selection. At the same time, we cannot ignore that these have been successfully addressed within the general field of subjectivity and the "unconscious" foundations of "rationality", especially those that influence the actions of information selection. Finally, they also confirm that there are no completely isolated individuals - absolutely singular -, nor a field of social or humanistic study where the general study of culture - as a study of the significant budgets of all actions - does not have a considerable influence.

It is also interesting to highlight this connection between Internet activity and the studies on subjectivity, because it gives a first idea of the "thematic" breadth and the wide field of knowledge that contemporary political studies must address, including the study of political beliefs. Here too, the notion of "event" offers advantages. A study of visibility on the Internet cannot be limited to the study of behavioral trends of a "connected" individual, since it is not possible to separate it from the study of the general mechanisms of intuition-based selection. At the same time, we cannot ignore that these have been successfully addressed within the general field of subjectivity and the "unconscious" foundations of "rationality", especially those that influence the actions of information selection. Finally, they also confirm that there are no completely isolated individuals - absolutely singular -, nor a field of social or humanistic study where the general study of culture - as a study of the significant budgets of all actions - does not have a considerable influence. 